now be given to the baby after delivery, though antigenaemia and clinical evidence of hepatitis occur less commonly when the mother is a true carrier than if acute hepatitis $B$ has occurred during the last trimester. Similarly, in adults the risks of exposure may also be greater in contacts of carriers with liver disease than in contacts of healthy carriers. ${ }^{8}$

It is within the hospital that the chances of cross-infection are greatest, particularly in the areas of blood transfusion and renal medicine. All personnel concerned must be screened at regular intervals for the antigen. Staff members found to be positive will have to be found other work, and HBAg-positive haemodialysis patients treated either at home or in one of the special isolation units that have been set up. Such precautions are already paying dividends in the reduction of serious epidemics of acute hepatitis $B$ in renal dialysis units and in creating fewer new carriers.

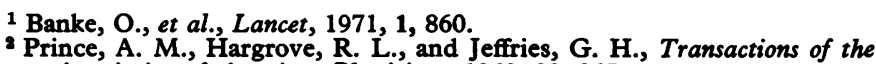
Association of American Physicians, 1969, 82, 265.

Bolin, T. D., Davis, A. E., and Liddelow, A. G., Gut, 1973, 14, 365.

Woolf, I. L., et al., Fournal of Clinical Pathology, 1974, 27, 348.

British Medical Fournal, 1974, 2, 518.

- Korman, M. G., Hofman, A. F., and Summerskill, W. H. J., New England Fournal of Medicine, 1974, 290, 1399.

Kaplowtiz, N., Kok, E., and Javitt, N. B., fournal of the American Medical Association, 1973, 225, 292.

Heathcote, J., Gateau, P., and Sherlock, S., Lancet, 1974, 2, 370.

- Szmuness, W., et al., New England fournal of Medicine, 1973, 289, 1162.

10 Reed, W. D., et al., Lancet, 1974, 1, 581.
}

\section{Respiratory Distress Syndrome in the Newborn}

Respiratory distress syndrome (R.D.S.) is the major cause of death in infants with a gestational age of less than 37 weeks ${ }^{1}$ and occurs in $10 \%$ of all preterm deliveries, ${ }^{2}$ with a mortality of around $50 \%$. Treatment still consists in maintaining the infant alive and without damage until the lung changes have resolved. Nevertheless much progress has been made during the last few years. In 1971 Gluck and his colleagues ${ }^{3}$ showed that the lecithin: sphingomyelin ratio in the liquor could be used to predict the maturity of the lung in terms of its ability to produce surfactant material; without surfactant material the infant will develop R.D.S. However Condorelli et al..$^{4}$ have shown that in sheep phospholipids can reach the amniotic fluid via extrapulmonary routes such as the fetal serum and urine. Reliable results with the ratio depend on careful handling of the specimen, attention to technical details, and an awareness that as little as $3.6 \mathrm{ml}$ of whole blood or $0.36 \mathrm{~g}$ of meconium (not enough to produce visible staining) per $100 \mathrm{ml}$ of amniotic fluid will affect the result. ${ }^{5}$

Gluck and his group ${ }^{6}$ have also found that certain maternal conditions can influence the ratio. An increase in the lecithin: sphingomyelin ratio indicating accelerated maturation is associated with chronic toxaemia, hypertensive renal disease, hypertensive cardiac disease, sickle cell disease, narcotic addiction, severe diabetes with vascular complications, circumvallate placenta, chronic retroplacental bleeding, and non-specific placental insufficiency. Conversely there is a retardation in the ratio in diabetes without vascular complications, chronic non-hypertensive glomerulonephritis, hydrops fetalis, and in the smaller of non-parasitic monochorionic twins, while in diabetes mellitus and severe rhesus disease ${ }^{7} 8$ there is a high incidence of anomalous results associated sometimes with the development of R.D.S. (or a condition indistinguishable from it) in spite of a normal ratio.
Rupture of the membranes for longer than 72 hours causes the ratio to rise ${ }^{9}$ and Bauer et al. ${ }^{10}$ found a decreased incidence of R.D.S. after rupture of the membranes for longer than 16 hours. These results have an important bearing on the management of rupture of the membranes before term, since serial estimations of the ratio can be made and delivery can be delayed until it has risen to a safe level; below 36 weeks the risk to the infant from R.D.S. is almost certainly greater than the risk from infection due to delay in delivery. In conditions such as placental insufficiency, moderately severe toxaemia, diabetes mellitus, and some cases of placenta praevia, where delivery before term is necessary but it is not an emergency, serial estimation of the ratio by amniocentesis can be used to determine when it is safe to effect delivery.

The obstetrician can make important contributions to the avoidance of R.D.S. Liggins ${ }^{11}$ showed that treatment of the mother with betamethasone for 24 hours before delivery reduced the risk of R.D.S., and Spellacy ${ }^{12}$ found a significant increase in the lecithin : sphingomyelin ratio after two weeks treatment with dexamethasone. Conduct of the preterm labour and delivery is important since intrapartum hypoxia (as shown by abnormal fetal heart rate patterns) is associated with an increased incidence of R.D.S. ${ }^{13}$ Nevertheless preterm delivery will continue to occur as a result of a spontaneous onset of labour, or when delivery is urgently indicated, as in eclampsia, severe toxaemia, antepartum haemorrhage, or placental abruption. Each N.H.S. area should surely come to an agreement that women in premature labour should be transferred for delivery to a unit fully equipped to deal with R.D.S. of all degrees of severity; infants with R.D.S. do not travel well.

The management of the infant with R.D.S. has been subject to many fancies and fallacies. Hypothermia and acidosis will interfere with the synthesis of surfactant material in the lung, ${ }^{14}$ and further deterioration can be prevented by treating the metabolic acidosis ${ }^{15}$ which inevitably accompanies intrapartum hypoxia or prolonged apnoea after delivery. Prompt resuscitation and the avoidance of cooling are therefore essential in the treatment of the infant already severely ill at delivery. Postnatal treatment of R.D.S. with corticosteroids has no obvious benefit. ${ }^{16} 17$

There has been much controversy over the use of mechanical ventilation in R.D.S.; results have been difficult to assess because centres have used different criteria for starting ventilation and have used ventilators with different characteristics. Reynolds and Taghizadeh ${ }^{17}$ have recently analysed their results at University College Hospital, London, over two three-year periods in which the infants treated were comparable. In 1967-69 they used very high peak airway pressures $(35-60 \mathrm{~cm}$ water) and rapid respiration rates $(60-80 /$ minute) but were often unable to achieve adequate oxygenation. In 1970-72 they used a "square-wave" pressure system with a high inspiratory : expiratory ratio $(>1: 1)$ and positive end-expiratory pressure to prevent alveolar collapse. Adequate oxygenation could be obtained using these methods with lower peak airway pressures, slower respiration rates, and a lower oxygen concentration in the inspired air. The overall survival rate for all cases of R.D.S. was $55 \%$ in the first period and $63 \%$ in the second period; of those mechanically ventilated the survival rates were $15 \%$ and $44 \%$ respectively. They attributed the improved survival to a reduction in bronchopulmonary dysplasia.

Gregory's paper ${ }^{18}$ on continuous positive airway pressure (C.P.A.P.) appeared in 1971 and the U.C.H. group started to use C.P.A.P. about halfway through its second period, but only for weaning of infants off the ventilator. Since 1971 the Gregory 
box system has been widely used; but it has been often proved difficult to set up and adjust. Modifications such as the cannulation of both nares ${ }^{2} 19$ have recently been described and make the system easier to use. Further trials are clearly needed of methods which do not require the high degree of medical and nursing skills and complex apparatus which the U.C.H. group have employed so successfully. What is required is a technique which can be set up quickly and easily in the special care unit of any maternity hospital.

1 Fedrick, J., and Butler, N. R., Biologia neonatorum, 1970, 15, 229.

2 Klaus, M. H., and Fanaroff, A. A., in Care of the High Risk Neonate. Philadelphia, W. B. Saunders, 1973.

Gluck, L., et al., American fournal of Obstetrics and Gynecology, 1971,

Condorelli, S., Cosmi, E. V., and Scarpelli, E. M., American fournal of Obstetrics and Gynecology, 1974, 118, 842.

5 Wagstaff, T. I., Whyley, G. A., and Freedman, G. A., Fournal of Obstetrics and Gynaecology of the British Commonwealth, 1974, 81, 264.

- Gluck, L., and Kulovich, M. V., American fournal of Obstetrics and Gynecology, 1973, 115, 539 .

7 Whitfield, C. R., et al., British Medical fournal, 1972, 2, 85.

8 Lemons, J. A., and Jaffe, R. B., American Fournal of Obstetrics and Gynecology, 1973, 115, 233.

Richardson, C. J., et al., American fournal of Obstetrics and Gynecology, 118, 1115-1118.

10 Bauer, C. R., Stern, L., and Colle, E., Pediatrics, 1974, 53, 7.

11 Liggins, G. C., and Howie, R. N., Pediatrics, 1972, 50, 515.

12 Spellacy, W. N., et al., American fournal of Obstetrics and Gynecology, $1973,115,216$.

13 Cohen, M. M., Weintraub, D. H., and Lilienfeld, A. M., Pediatrics, 1960, 26, 42.

14 Gluck, L., et al., Pediatric Research, 1972, 6, 81

14 Gluck, L., et al., Pediatric Research, 1972, 6, 81. 118.

${ }_{16}^{15}$ Bobel, C. J., et al., Fournal of Pediatrics, 197

17 Reynolds, E. O. R., and Taghizadeh, R., Archives of Disease in Childhood, $1974,49,505$.

18 Gregory, G. A., et al., New England fournal of Medicine, 1971, 284, 1333. 19 Caliumi-Pellegrini, G., et al., Archives of Disease in Childhood, 1974, 49, 228.

\section{Fourth, Fifth, and Sixth}

Scarlet fever, rubella, and measles are first, second, and third. Fourth, if it exists, is Filatow-Dukes's disease, fifth is erythema infectiosum, and sixth is exanthum subitum.

Fourth disease was carefully described by Filatow $^{1}$ in 1885 and by Dukes ${ }^{2}$ in 1900 . Strawberry tongue, desquamation, and albuminuria were among its features, so it may well have been an unusual form of scarlet fever. If it was a disease sui generis, it seems never to have recurred this century.

Fifth disease, though apparently uncommon in Britain, has been reported ${ }^{3}{ }^{4}$ frequently in localized outbreaks elsewhere. Its official name is erythema infectiosum, but it is also known in America 56 as "slapped cheek disease." The rash is most prominent on the cheeks, where it first appears as bright macules which finally run into one another: it does not rise above the malar bones nor run across the mouth, so the term "slapped cheek" is an apt descriptive one. The rash later comes out on the limbs and, very sparsely, on the trunk, but it is always less bright there: it has been described as lace-like, reticular, annular, or serpentine, but in truth it is rather nondescript. It persists for a week or ten days. Other symptoms are slight and vague-malaise, a few aches, or headache-and there are no after-effects. It occurs in sharp outbreaks, often in school children, its main age incidence being on the 2-14-year-old age group. The incubation period is around 4 to 14 days, it seems to spread by droplet infection, and it is probably a virus disease. Two recent cases in young children are described at p.466.

Sixth disease affects usually children between 6 months and 2 years of age. Its commoner names today are exanthem subitum or roseola infantum. It has also been called "three-day fever": this name is undesirable because it might lead to confusion with dengue, but it does draw attention to the main characteristic of the disease, namely fever, though this may last longer than three days. The fever comes on abruptly and the temperature may run at about $39-40^{\circ} \mathrm{C}\left(103-105^{\circ} \mathrm{F}\right)$ for three to five days. The infant often seems bright and alert in spite of this high fever, but occasionally an infant has a convulsion. When the fever subsides a rash appears, first on the upper trunk then spreading to the neck and limbs. It consists of fine pink macules which do not coalesce and are fleeting and easy to miss. Leucopenia is common after the first day, which suggests that this is yet another virus disease. It may occur in sharp outbreaks, ${ }^{7}$ but many infants seem to have the fever without the rash, and this may obscure the epidemic picture. One outbreak was described in a maternity hospital when the disease spread to nurses and parents, ${ }^{8}$ but normally this sudden exanthematous disease remains a roseola of infants.

\footnotetext{
1 Harries, E. H. R., and Mitman, M., in Clinical Practice in Infectious Diseases. Edinburgh, Livingstone, 1951

2 Dukes, C., Lancet, $1900,2,89$.

Ager, E. A., Chin, T. D. Y., and Poland, J. D., New England fournal of Medicine, 1966, 275, 1326.

Edelson, R. N., and Altman, R., fournal Medical Society of New fersey, $1970,67,805$.

Ager, E. A., in Communicable and Infectious Diseases, Ed. F. H. Top, and F. F. Wehrle, St. Louis, C. V. Mosby, 1972.

Marcy, S. M., and Kibrick, S., in Infectious Diseases, ed. P. D. Hoeprich, Hagerston, Maryland, Harper and Row, 1972.

Hagerston, Maryland, Harper and Row, 1972.
Clemens, H., fournal of Pediatrics, 1945, 26, 66.

8 James, Ursula, and Freier, A., Archives of Disease in Childhood, 1949, 24, 54.
}

\section{International Views on Alcohol and Traffic Safety}

The problem of the drinking driver was recognized very shortly after motor cars appeared on the road, and last month the sixth international conference on the subject took place in Toronto. Almost everywhere in the world recently the consumption of alcohol has risen, there are more alcoholics, and both the speed and density of traffic has increased, making the results of collisions more serious. The disappointing message delivered to 700 representatives from more than 30 countries was that (with the possible exception of the United Kingdom) legislative programmes have made no real impact on the problem.

There was much interest at the conference in the reasons why the dramatic savings in casualties in Britain which followed the 1967 Road Safety Act have not been sustained. Even Professor H. L. Ross of Denver, who was highly critical of the successes claimed by the Scandinavian countries for their legislation, acknowledged that the United Kingdom had achieved important results. His time-series analysis had suggested that the initial effect was due to the firm belief among drivers that they would probably be caught if they drove after drinking. Court cases had been publicized by the press, keeping the law at the front of the drinking driver's mind. More recently, thought Professor Ross, it seemed that British drivers had realized that the risk of detection was really very low and were starting to take risks again. Scandinavian experience (where drinking drivers comprise $10 \%$ of the prison population) suggested that the probability of detection was more important than the severity of the punishment. Automatic disqualification was an important deterrent, and countries which had automatic conviction at a given blood level achieved better results than those in which it was left to a court to decide whether or not an offence had been committed. The British practice of allowing a police officer 